\title{
ORIGINAL ARTICLE Prevalence of vitamin D deficiency and association with metabolic syndrome in a Qatari population
}

\author{
K Al-Dabhani ${ }^{1}$, KK Tsilidis ${ }^{1,2}$, N Murphy ${ }^{1,3}$, HA Ward $^{1}$, P Elliott ${ }^{1,4}$, E Riboli ${ }^{1}$, M Gunter $^{3}$ and I Tzoulaki $^{1,2,4}$
}

\begin{abstract}
OBJECTIVES: Despite long hours of sunlight in Qatar and other regions of the Middle East, vitamin D deficiency has been rising. In parallel, the prevalence of metabolic syndrome has also been increasing in Qatar. Vitamin D levels have been associated with metabolic syndrome but the data are inconsistent and no studies have addressed these inter-relationships in a Middle Eastern population where the prevalence of these conditions is high. The objective is to investigate the prevalence of vitamin D deficiency and its association with metabolic syndrome and its components in the Qatar Biobank population.

METHODS: A cross-sectional study of 1205 participants (702 women and 503 men) from the Qatar Biobank, comprising Qataris and non-Qataris between the ages of 18 and 80 years, was used to perform multivariate linear regression analyses to examine the association between metabolic syndrome and prevalence of vitamin D deficiency (defined as $<20 \mathrm{ng} \mathrm{ml}^{-1}$ serum vitamin D levels) adjusting for age, sex, ethnicity, season of blood collection, physical activity and education. Odds ratios and $95 \%$ confidence intervals were calculated for all analyses.

RESULTS: Approximately $64 \%$ of participants were vitamin D deficient ( $<20 \mathrm{ng} \mathrm{ml}^{-1}$ ) with more men being deficient (68.6\%) than women (61.3\%). Serum vitamin D was $8 \%$ lower in individuals with metabolic syndrome (RR: $0.92,95 \%$ Cl: $0.87-0.98, P$-value: 0.01 ) compared to individuals without metabolic syndrome. Waist circumference and HDL as well as high triglyceride levels were also significantly positively associated with vitamin D deficiency. No association was found between the other components of metabolic syndrome or diabetes and the presence of vitamin D deficiency.
\end{abstract}

CONCLUSIONS: Vitamin D deficiency is prevalent in this Qatari population. Presence of metabolic syndrome was associated with presence of vitamin D deficiency. Future prospective studies need to be conducted to investigate the potential for causality.

Nutrition \& Diabetes (2017) 7, e263; doi:10.1038/nutd.2017.14; published online 10 April 2017

\section{INTRODUCTION}

Vitamin D deficiency is highly prevalent worldwide and is associated with many adverse health outcomes. ${ }^{1,2}$ Vitamin $D$ is acquired in three ways; from sun exposure, diet and supplements; however, the greatest proportion is obtained from sun exposure. For example, exposure to 0.5 minimal erythemal dose is equivalent to supplementing $\sim 3000 \mathrm{IU}$ of vitamin $\mathrm{D}_{3}{ }^{1}$. One of the main physiological functions of vitamin $D$ is to maintain calcium and phosphorous levels in the body to sustain various metabolic functions, including bone metabolism. ${ }^{3}$ The most abundant circulating biomarker of vitamin $\mathrm{D}$ status is 25hydroxyvitamin $D(25(\mathrm{OH}) \mathrm{D})$, which also has a longer half-life (25 days) compared to the active metabolite; 1,25-dihydroxyvitamin $D(7 \mathrm{~h}) .{ }^{4}$ However, the threshold used to define vitamin D deficiency often varies according to the population and outcome of interest. $^{5-7}$ The most common definition for optimal $25(\mathrm{OH}) \mathrm{D}$ levels is the concentration at which it supresses the parathyroid hormone to its minimum, however, using this definition results in a wide range of minimal optimal values from $12 \mathrm{ng} \mathrm{ml}^{-1}$ to $40 \mathrm{ng} \mathrm{ml}^{-1}$.

A number of studies have shown that vitamin D levels are inversely associated with the risk of a diverse set of diseases, including several cancers, diabetes and cardiovascular diseases. $^{8-12}$ The association between vitamin $D$ levels and a range of disease outcomes could be explained by intermediate disease risk factors such as the metabolic syndrome (MetS); a constellation of risk factors, including increased obesity, hypertriglyceridemia, hypertension and diabetes. Some studies have suggested an inverse associations between serum vitamin $D$ and MetS, ${ }^{2,12-16}$ while others have not confirmed this observation. ${ }^{17,18}$ It is also unclear which components of the MetS might drive this association with vitamin D with some studies, suggesting obesity and others glucose haemostasis. ${ }^{12,16,19,20}$

Despite the long hours of sunlight in Qatar and surrounding regions, vitamin $\mathrm{D}$ deficiency has been shown to be highly prevalent in this region. ${ }^{21-26}$ For example, a Kuwaiti and an Emirati study reported that $\sim 98$ and $83 \%$ (respectively) of the participants had serum $25(\mathrm{OH}) \mathrm{D}$ less than $20 \mathrm{ng} \mathrm{ml}^{-1} \cdot 24,25$ Studies thus far conducted in Qatar on vitamin D were specific to a certain population (elderly and health professionals). At the same time, the prevalence of MetS was measured to be $\sim 26.5 \%$, according to the International Diabetes Federation (IDF) criteria, amongst Qataris aged 20 and over. ${ }^{27}$ Similarly, there was a high prevalence of MetS, according to both the IDF and Adult Treatment Panel (ATPIII) criteria, and its components in neighbouring regions. ${ }^{28-31}$ Given the high prevalence of these two conditions in the region and the limited epidemiological evidence in this population so far, we aimed to investigate the prevalence of vitamin D deficiency, as

\footnotetext{
${ }^{1}$ Department of Biostatistics and Epidemiology, School of Public Health, Imperial College London, London, UK; ${ }^{2}$ Department of Hygiene and Epidemiology, University of loannina

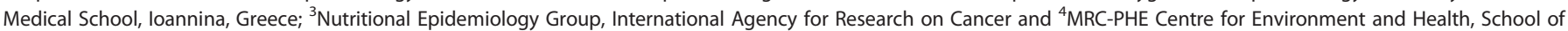

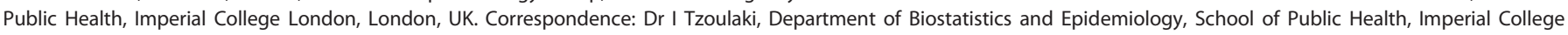
London, St Mary's Campus, London, W2 1NY UK.
}

E-mail: i.tzoulaki@imperial.ac.uk

Received 10 October 2016; revised 26 January 2017; accepted 13 February 2017 
well as the association between MetS and its components with vitamin D, in the well-characterised Qatar Biobank.

\section{MATERIALS AND METHODS}

\section{Data source}

The data for this study was obtained from the Qatar Biobank (QBB), which consisted of 1205 participants; with 702 females and 503 males, at the time of investigation. Participants who were either Qatari or non-Qataris but who were long-term residents of Qatar (that have lived there for over 15 years) were included in the cohort. Recruitment for these participants occurred mostly by personal recommendations of friends and family between December 2012 and February 2014. Participation was voluntary and registration was conducted via online and telephone bookings. A maximum of 10 participants were seen per day. All participants gave informed consent. Detailed methods for recruitment and study design have been reported elsewhere. ${ }^{32}$ Questionnaires on health, lifestyle, and diet were completed. Anthropometric measurements and body composition were also obtained. Biological samples, including blood, a urine sample and a saliva sample, were collected from each participant after the questionnaires were filled out.

A total of 66 clinical biomarkers (including bone and joint markers, coagulation tests, diabetes related tests, differential white cell count, full blood count, sex steroid hormones, lipid profile, minerals and vitamins) were routinely measured for all participants. Haematology and blood biochemistry were analysed by the laboratories at Hamad Medical Corporation (HMC).

\section{Exposure and outcome assessments}

Vitamin D assessment. 25(OH)D was analysed in one lab at HMC, which is College of American Pathologist (CAP) accredited, using a LIAISON $25 \mathrm{OH}$ Vitamin D TOTAL Assay, where serum $25(\mathrm{OH}) \mathrm{D}_{2}$ and $25(\mathrm{OH}) \mathrm{D}_{3}$ were measured. In this study, vitamin $D$ deficiency was defined by the US Endocrine Society (USES) guidelines as $<20 \mathrm{ng} \mathrm{ml}^{-1}\left(50 \mathrm{nmoll}^{-1}\right)$ in circulation, while individuals with $21-29 \mathrm{ng} \mathrm{ml}^{-1}$ were considered insufficient, and individuals with $>30 \mathrm{ng} \mathrm{ml}^{-1}$ were considered sufficient. $^{33}$ To convert between $\mathrm{ng} \mathrm{ml}^{-1}$ and nmol $\mathrm{l}^{-1}$ of $25(\mathrm{OH}) \mathrm{D}$, multiply the concentration of $25(\mathrm{OH}) \mathrm{D}$ in $\mathrm{ng} \mathrm{m}^{-1}$ by 2.5 .

Anthropometric measures. Weight, height, body mass index (BMI), and waist and hip circumference were all measured by a trained nurse. Participants wore gowns or light weight clothing, and shoes and socks were removed. Weight was measured using the TANITA BC-418 MA instrument; a multi-frequency segmental body composition analyser, or a digital floor scale Seca-876 for manual weight measurement when TANITA was contraindicated. BMI was calculated as weight in kilogram divided by height in metres squared $\left(\mathrm{kg} \mathrm{m}^{-2}\right)$. Waist and hip measurements were measured using a non-stretchable sprung measuring tape by Seca. The waist was identified as the smallest part of the trunk after folding their arms across their chest. If it was not possible to find a natural indent of the trunk, the circumference around the umbilicus was measured in centimetres. For the hip measurement, the Seca measuring tape was placed at the widest part of the hips and measured in centimetres. Waistto-hip ratio was calculated as waist in centimetres divided by hip circumference also in centimetres.

Metabolic syndrome components. Metabolic syndrome was defined according to the new IDF definition as being centrally obese (defined as waist circumference $\geqslant 94 \mathrm{~cm}$ for males and $\geqslant 80 \mathrm{~cm}$ for females) as well as at least two of the following four factors: (1) raised triglycerides $\left(\geqslant 1.7 \mathrm{mmol} \mathrm{I}^{-1}\right)_{1}^{2}(2)$ reduced $\mathrm{HDL}$ cholesterol $\left(<1.03 \mathrm{mmol} \mathrm{I}^{-1}\right.$ in males and $<1.29 \mathrm{mmol} \mathrm{I}^{-1}$ for females), (3) raised blood pressure (BP) (systolic $B P \geqslant 130 \mathrm{~mm} \mathrm{Hg}$ or diastolic $B P \geqslant 85 \mathrm{~mm} \mathrm{Hg}$ ), (4) raised fasting plasma glucose (defined as $\mathrm{HbA} 1 \mathrm{c}$ levels $\geqslant 5.7 \mathrm{mmol}^{-1}$ ). ${ }^{34} \mathrm{HbA} 1 \mathrm{c}$ was measured with turbidimetric inhibition immunoassay (TINIA). Cholesterol was measured using CHOD-PAP GEN2 STAND ID/MS, HDL was measured using the HDL-C plus third generation, LDL was measured using the LDL-C plus second generation and triglyceride was measured using GPO-PAP.

Blood pressure was measured by a trained nurse using an Omron M10-IT automated upper arm blood pressure monitor with arm cuffs of different sizes. The reading was collected twice if the results were similar, but if different (differed by more than $5 \mathrm{~mm} \mathrm{Hg}$ ) a third measurement was performed. The participant rested for $30 \mathrm{~s}$ between the measurements.
If the measurements did not differ, the average of the first two measurements was taken. However, if the measurements did differ, the average of the second and third measurement was used. Diabetes was reported in two ways: (1) self-reported; where 15.4\% reported having diabetes and (2) laboratory measurements of $\mathrm{HbA1c}$ levels $(\geqslant 6.5 \%$ was considered evidence for diabetes), ${ }^{35}$ where $17.4 \%$ of participants were considered diabetic.

\section{Statistical analysis}

To test the difference in the distributions of categorical variables, a $X^{2}$ test was performed, while a $t$-test was performed to test the differences between a categorical and a continuous variable after stratifying by sex. A geometric mean for serum $25(\mathrm{OH}) \mathrm{D}$ was calculated by performing a oneway Analysis of Covariance (ANCOVA) adjusting for sex, age and season of blood collection. Partial Spearman's correlation coefficient was used to measure the cross-sectional association between anthropometric measurements, circulating lipids, haemoglobin $\mathrm{A} 1 \mathrm{c}(\mathrm{HbA1c})$, glucose, insulin, C-peptide, folate, vitamin D, calcium and SHBG.

Vitamin D was modelled as a continuous measurements. Metabolic syndrome and its components were categorised into having abnormal levels or normal levels based on the IDF definition. ${ }^{34}$ Univariate (crude) and multivariable linear regression models were used to calculate the regression coefficients and associated 95\% confidence intervals (CI). Multivariable model (Model 2) was adjusted for age (continuous), sex, ethnicity, education, physical activity and season. Participants with missing ethnicity values $(n=242)$ were excluded from all analyses.

\section{RESULTS}

\section{Descriptive characteristics}

Approximately $58 \%$ of the study population were females; mean age was similar between males and females (Table 1). There were several differences between males and females with regards to anthropometric factors: men had more visceral fat $(97 \mathrm{~cm})$ than women $(85 \mathrm{~cm})$ and also reported to smoke more and exercise more frequently (39\% and $19 \mathrm{~h}$ per week, respectively) than women (12\% and $11 \mathrm{~h}$ per week, respectively). BMI as well as the prevalence of diabetes $(\sim 15 \%)$ and metabolic syndrome ( 28\%) were similar between males and females (Table 1 ).

Approximately $64 \%$ of the participants in this study were vitamin D deficient $\left(<20 \mathrm{ng} \mathrm{ml}^{-1}\right)$ with slightly more men $(69 \%)$ being vitamin $D$ deficient compared to women (61\%). Another $25 \%$ of the population had insufficient vitamin D levels. Table 1 reports the prevalence of stages of vitamin D deficiency according to USES definitions. ${ }^{33}$ The percentage of people reported taking vitamin D supplements was high with $49 \%$ of females and $25 \%$ of males (Table 1). Women were more likely to undergo vitamin $D$ screening, and take vitamin D and calcium supplements compared to men.

Table 2 shows crude and adjusted mean vitamin D levels across categories of participant characteristics. Females reported a higher concentration of serum $25(\mathrm{OH}) \mathrm{D}$ compared to males in both the adjusted and unadjusted mean $25(\mathrm{OH}) \mathrm{D}$, although this difference was not statistically significant. Also, higher $25(\mathrm{OH}) \mathrm{D}$ levels were observed in older compared to younger participants. The remaining characteristics did not show differences according to 25(OH)D levels.

Associations between metabolic syndrome, vitamin $D$ deficiency and serum $25(\mathrm{OH}) \mathrm{D}$ levels

Table 3 reports the association between metabolic syndrome with the risk of vitamin D deficiency ( $<20 \mathrm{ng} \mathrm{ml}^{-1}$ ) and serum $25(\mathrm{OH})$ $D$ levels. There was a significant positive association between the presence of MetS and vitamin D deficiency after adjusting for Model 2 (OR: 1.54, 95\%Cl: 1.09-2.18) (Supplementary Table 1). However, age was the main confounder responsible for the statistical significant association between MetS and its components with $25(\mathrm{OH}) \mathrm{D}$ concentration. The presence of MetS was associated with lower 25(OH)D levels (RR per $\mathrm{ng} \mathrm{ml}^{-1}$ : 0.92 , 
Table 1. Main characteristics of Qatar Biobank study participants stratified by sex

\begin{tabular}{|c|c|c|c|}
\hline \multirow[t]{2}{*}{ Characteristic } & $\begin{array}{l}\text { Females } \\
(\mathrm{N}=702)\end{array}$ & $\begin{array}{c}\text { Males } \\
(N=503)\end{array}$ & $\begin{array}{c}\text { Total } \\
(N=1205)\end{array}$ \\
\hline & Mean (s.d.) & Mean (s.d.) & Mean (s.d.) \\
\hline Age (IQR) $(N=1205)$ & $39.3(28-50)$ & $40.8(30-51)$ & $39.9(29-50)$ \\
\hline $\operatorname{Sex}^{\mathrm{a}}(\%)(N=1205)$ & 58.2 & 41.8 & \\
\hline BMI $\left(\mathrm{kg} \mathrm{m}^{-2}\right)(N=1199)$ & $29.0(6.8)$ & $28.7(5.5)$ & $28.9(6.3)$ \\
\hline Height $(\mathrm{cm})(N=1203)$ & $158.4(6.0)$ & $172.5(6.6)$ & $164.3(9.3)$ \\
\hline Weight $(\mathrm{kg})(N=1199)$ & $72.6(17.2)$ & $85.5(18.1)$ & $78.0(18.7)$ \\
\hline $\begin{array}{l}\text { Waist circumference }(\mathrm{cm}) \\
(N=1994)\end{array}$ & $85.0(14.7)$ & $97.2(13.6)$ & $90.1(15.5)$ \\
\hline WHR $(N=1194)$ & $0.8(0.1)$ & $0.9(0.1)$ & \\
\hline \multicolumn{4}{|l|}{ Education $^{\mathrm{a}}(\%)(\mathrm{N}=1202)$} \\
\hline Less than primary school & 4.0 & 0.2 & 2.4 \\
\hline Primary school & 4.3 & 2.0 & 3.3 \\
\hline Secondary school & 5.3 & 7.2 & 6.1 \\
\hline Technical/professional school & 22.1 & 22.9 & 22.5 \\
\hline University/postgraduate & 74.2 & 67.7 & 65.7 \\
\hline \multicolumn{4}{|l|}{ Smoking status ${ }^{\mathrm{a}}(\%)(\mathrm{N}=668)$} \\
\hline Never smoked & 86.0 & 47.7 & 59.6 \\
\hline Stopped smoking & 1.4 & 13.7 & 9.9 \\
\hline Once/twice & 7.2 & 6.5 & 6.7 \\
\hline Occasionally & 1.9 & 10.0 & 7.5 \\
\hline Smoke on most/all days & 3.4 & 22.1 & 16.3 \\
\hline \multicolumn{4}{|l|}{ Ethnicity $^{\mathrm{a}}(\%)(\mathrm{N}=954)$} \\
\hline Non-Qatari & 18.6 & 39 & 27.4 \\
\hline Qatari & 81.4 & 61.0 & 72.6 \\
\hline \multicolumn{4}{|l|}{ Season of blood draw ${ }^{\mathrm{a}}(\%)(\mathrm{N}=1205)$} \\
\hline Winter ${ }^{b}$ & 33.0 & 33.8 & 33.4 \\
\hline Spring $^{\mathrm{b}}$ & 22.9 & 33.0 & 27.1 \\
\hline Summer ${ }^{b}$ & 14.2 & 13.3 & 13.9 \\
\hline Fall $^{\mathrm{b}}$ & 29.8 & 19.9 & 25.6 \\
\hline $\begin{array}{l}\text { MET score (h per week) } \\
(N=1205)\end{array}$ & $10.8(24.8)$ & $19.5(43.8)$ & $14.5(34.3)$ \\
\hline $\begin{array}{l}\text { Self-reported diabetic }{ }^{a}(\%) \\
(N=1198)\end{array}$ & 14.6 & 16.4 & 15.3 \\
\hline $\begin{array}{l}\text { Metabolic syndrome }{ }^{\mathrm{a}}(\%) \\
(N=1205)\end{array}$ & 29.2 & 27.8 & 28.6 \\
\hline $\begin{array}{l}\text { Vitamin D supplementation }{ }^{\mathrm{a}}(\%) \\
(N=1205)\end{array}$ & 49.0 & 24.8 & 38.9 \\
\hline \multicolumn{4}{|c|}{ 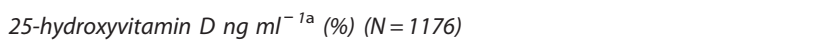 } \\
\hline $\begin{array}{l}\text { Severely deficient } \\
\left(<10 \mathrm{ng} \mathrm{m}^{-1}\right)\end{array}$ & 10.6 & 5.8 & 8.6 \\
\hline Deficient $\left(10-<20 \mathrm{ng} \mathrm{ml}^{-1}\right)$ & 50.7 & 62.8 & 55.8 \\
\hline Insufficient $\left(20-<30 \mathrm{ng} \mathrm{ml}^{-1}\right)$ & 26.1 & 24.7 & 25.5 \\
\hline Sufficient $\left(\geqslant 30 \mathrm{ng} \mathrm{ml}^{-1}\right)$ & 12.7 & 6.6 & 10.1 \\
\hline
\end{tabular}

Abbreviations: MET, Metabolic equivalent; WHR, waist-to-hip ratio ${ }^{a}$ Categorical variables with (\%) indicate percentages rather than means and standard deviation. The percentages were taken after removing missing, prefer not to answer, and I do not know categories. ${ }^{b}$ Seasons defined as winter: December-February, spring: March-May, summer: JuneAugust, and fall: September-November.

95\% Cl: 0.86-0.98). Components of the MetS that were inversely associated with serum $25(\mathrm{OH}) \mathrm{D}$ levels, including high waist circumference (high vs normal, $\mathrm{RR}$ per $\mathrm{ng} \mathrm{ml}^{-1}: 0.94,95 \% \mathrm{Cl}$ : 0.88-0.99) and elevated triglycerides (high vs normal, RR: 0.90, 95\% Cl: 0.84-0.95). While increasing levels of HDL was positively associated with $25(\mathrm{OH}) \mathrm{D}$ levels (per $\mathrm{mmol}^{-1}$ increase RR: 1.12, 95\% Cl: 1.03-1.21). Elevated blood pressure showed weak inverse association with vitamin $D$; the association was stronger with the presence of vitamin D deficiency (OR for high vs normal: 1.60, 95\% Cl: 1.06-2.42, $P$-value: 0.03 ) (Supplementary Table 1) compared to 25(OH)D levels; (RR per one unit increase: $0.93,95 \% \mathrm{Cl}$ : $0.86-1.00$, $P$-value: 0.06$)$. The association between vitamin $\mathrm{D}$ deficiency or 25
$(\mathrm{OH}) \mathrm{D}$ levels with presence of diabetes was not statistically significant.

\section{DISCUSSION}

In this unique study in Qatar, we showed that despite being a country with high levels of sun exposure, the prevalence of vitamin D deficiency is very high (64\%), with the majority of the examined population showing signs of deficiency. This is consistent with previous observations which estimated the prevalence of vitamin deficiency $(<20 \mathrm{ng} / \mathrm{ml})$ to range between $72-87 \% .{ }^{22,26}$ At the same time, the percentage of participants reporting supplementation for vitamin $D$, especially in women was very high (49\%), higher than that observed in white populations, ${ }^{36-38}$ potentially showing a greater awareness of vitamin $\mathrm{D}$ deficiency in this population.

Approximately $64 \%$ of the participants in the Qatar Biobank were vitamin $D$ deficient $\left(<20 \mathrm{ng} \mathrm{ml}^{-1}\right)$, with slightly more men being deficient compared to women. Previous evidence from studies in the Middle East region supports higher level of vitamin $D$ in males compared to females. A Saudi Arabian study performed on 10709 participants reported more females being severely vitamin $D$ deficient $\left(<10 \mathrm{ng} \mathrm{ml}^{-1}\right)$ compared to males. ${ }^{23}$ A Bahraini and Lebanese study also reported lower mean serum vitamin $D$ in females compared to males. ${ }^{21,39}$ One hypothesis for this difference could be explained by vitamin D supplementation, as women in the Qatar Biobank were more likely to take vitamin D supplements compared to men. This was not reported in both the Saudi and Bahraini studies due to exclusion of participants that consumed vitamin D supplements. ${ }^{21,23}$

MetS was significantly associated with the risk of vitamin D deficiency in the Qatar BioBank. Several cross-sectional and few prospective studies have reported similar positive associations between vitamin $D$ deficiency and the risk of metabolic syndrome. ${ }^{12,15,40-42}$ In addition, prospective studies from the PROMISE cohort and the Australian Diabetes, Obesity and Lifestyle (Aus-Diab) study, reported significant inverse associations between continuous serum vitamin $\mathrm{D}$ and overall MetS, based on the IDF criteria. ${ }^{12,40}$ Studies examining the direction of the effect between vitamin $D$, cholesterol and lipids suggest that lipids levels and BMI may be a cause for decreased vitamin D and not vice versa. ${ }^{43,44}$ Other cross-sectional studies did not support these associations. ${ }^{45,46}$ However, this might have been due to the small sample sizes ${ }^{45,47}$ and small variation in the exposure (e.g. high levels of vitamin $D$ in the study by Reis et al. in both men and women). ${ }^{46}$ Studies on Middle Eastern population where the metabolism of vitamin $D$ could be different due to different lifestyles and darker skin pigmentation, are very limited and our results support an inverse association between the two examined phenotypes.

Many mechanisms have been proposed to explain the association between vitamin D and future risk of MetS component. Since vitamin $D$ is fat soluble and could be stored in adipose tissue, it can be sequestered in the subcutaneous fat in obese individuals, reducing the levels of circulating vitamin $D$ in the blood leading to less release of vitamin $D$ into the blood. ${ }^{48,49}$ Vitamin $D$ has also been shown to inhibit the release of cytokines from the immune cell, which is harmful to $\beta$ cells. ${ }^{50}$

Obesity, measured as BMI, waist circumference, and waist-to-hip ratio were positively associated with vitamin $D$ deficiency with stronger associations observed with waist circumference. Similar results were found in both prospective and cross-sectional studies, including the Aus-Diab study, ${ }^{40}$ the British Birth Cohort, ${ }^{47}$ Middle Eastern populations, ${ }^{25,51}$ and in other populations around the world. ${ }^{15,52,53}$ Conversely, several cross-sectional studies did not report a correlation between obesity and vitamin D deficiency. ${ }^{45,46,54}$ However, these are mainly small studies with limited power to observe associations. ${ }^{45,46}$ We also showed that 
Table 2. Unadjusted and adjusted mean 25-hydroxyvitamin D levels by participant characteristics

\begin{tabular}{|c|c|c|c|c|c|}
\hline Characteristics & Unadjusted mean 25(OH)D (s.d. $)^{\mathrm{a}}$ & P-value & Adjusted mean 25(OH)D (s.d. $)^{\mathrm{b}}$ & P-value & P-Trend \\
\hline Female $(N=679)$ & $19.0(10.0)$ & & $17.0(0.1)$ & & \\
\hline$<25(N=140)$ & $15.1(9.1)$ & & $13.5(0.0)$ & & \\
\hline $25-34(N=352)$ & $16.7(9.2)$ & & $15.0(0.0)$ & 0.01 & \\
\hline $35-44(N=224)$ & $18.4(9.5)$ & & $16.6(0.0)$ & $<0.001$ & \\
\hline Education $(N=1173)$ & & $<0.001$ & & & 0.46 \\
\hline Less than primary school $(N=29)$ & $23.1(8.7)$ & & $21.4(0.1)$ & & \\
\hline Primary school $(N=39)$ & $23.9(10.7)$ & & $22.1(0.1)$ & 0.53 & \\
\hline Secondary School $(N=69)$ & $19.3(6.8)$ & & $18.1(0.1)$ & 0.72 & \\
\hline Technical/Professional school $(N=263)$ & $17.5(11.4)$ & & $15.5(0.1)$ & 0.17 & \\
\hline University/Postgraduate $(N=773)$ & $18.3(9.0)$ & & $16.8(0.1)$ & 0.64 & \\
\hline Smoking status $(N=656)$ & & 0.14 & & & 0.92 \\
\hline Ethnicity $(N=934)$ & & $<0.001$ & & & 0.29 \\
\hline Non-Qatari $(N=261)$ & $17.6(6.5)$ & & $17.2(0.1)$ & & \\
\hline Qatari $(N=673)$ & $18.5(9.2)$ & & $16.7(0.1)$ & 0.29 & \\
\hline Season blood draw $(N=1176)$ & & 0.99 & & & 0.43 \\
\hline Winter $^{c}(N=400)$ & $18.5(10.2)$ & & $17.1(0.1)$ & & \\
\hline Spring ${ }^{\mathrm{C}}(N=318)$ & $18.6(8.8)$ & & $16.8(0.1)$ & 0.46 & \\
\hline Summer $^{c}(N=164)$ & $18.2(9.1)$ & & $16.8(0.1)$ & 0.62 & \\
\hline Autumnc $(N=294)$ & $18.9(9.7)$ & & $16.4(0.1)$ & 0.41 & \\
\hline MET score (h per week) $(N=1176)$ & & 0.24 & & & 0.15 \\
\hline $0(N=415)$ & $18.8(10.3)$ & & $16.8(0.1)$ & & \\
\hline$>0-9.99(N=401)$ & $18.5(8.2)$ & & $16.9(0.1)$ & 0.77 & \\
\hline $10-49.99(N=281)$ & $18.0(7.5)$ & & $16.5(0.1)$ & 0.73 & \\
\hline$\geqslant 50(N=79)$ & $20.4(14.6)$ & & $17.9(0.1)$ & 0.02 & \\
\hline
\end{tabular}

Abbreviation: MET, metabolic equivalent. ${ }^{a}$ An ANCOVA test was used to measure significance. ${ }^{b}$ Mean vitamin D was adjusted for age, sex and season of blood collection. 'Seasons defined as Winter: December-February, Spring: March-May, Summer: June-August, and Autumn: September-November.

high triglyceride levels were associated with lower levels of vitamin D. Studies also report significant inverse associations between vitamin $D$ with high triglyceride levels. ${ }^{52,55}$ However, when stratified by sex, only the association in men remained significant in the Ling et al. study. ${ }^{52}$ On the contrary, Reis et al. reported a positive trend between vitamin D deficiency and high triglyceride levels only in women. ${ }^{46}$

This is the first study of vitamin D and metabolic syndrome performed in the Qatari population and long-term residents $(\geqslant 15$ years living in Qatar) with high-quality data, which involves collection of extensive questionnaire information, clinical phenotyping and biological samples. ${ }^{32}$ Qatar Biobank, as of yet is not considered to have a fully representative sample, since the most common source of participant recruitment is through word of mouth to friends and families. ${ }^{32}$ However, the population of our study shows small differences with the Qatar Stepwise Survey (QSS), which is based on the WHO STEPS survey and consists of 2 496 participants. In the QSS, measurements of height, weight, and BMI were similar to this study. However, in Qatar Biobank, over $60 \%$ of the participants had a university degree compared to $35 \%$ of the QSS, ${ }^{56}$ suggesting a higher representation of more educated and higher socioeconomic status individuals in Qatar Biobank.

Since this study is cross-sectional, the directionality of the relationship between adiposity, vitamin $D$, metabolic syndrome, and diabetes could not be elucidated. The non-significant results for the association between diabetes and vitamin D deficiency, may have been due to the relatively small sample size and low response rate for some questions regarding physical activity, smoking, supplements and so on. It could also have been due to other confounding factors such as specific medication use and dosage of supplements, which were not captured. Approximately $84 \%$ of participants were missing data on medication use for hypertension and $68 \%$ of participants were missing for medication on cholesterol usage, which may have caused some misclassification. Additionally, the low levels of circulating vitamin D found in this population may have been insufficient to observe any inverse relationships with metabolic syndrome components and diabetes.

To conclude, the findings from this study support a positive association between the presence of metabolic syndrome and vitamin D deficiency. We also observed that MetS components, such as obesity and high triglyceride, were inversely associated with circulating serum vitamin $D$ levels. Future prospective studies should elucidate the potential causal association between vitamin D and MetS using Mendelian randomisation approaches or through supplementation with Vitamin D. Moreover, mechanistic studies should concentrate on identifying pathophysiological pathways and molecular mechanisms linking vitamin D deficiency and metabolic syndrome. 
Table 3. Linear regression analyses between metabolic syndrome and its components with vitamin D

\begin{tabular}{|c|c|c|c|c|}
\hline & \multicolumn{4}{|c|}{ Per $\mathrm{ng} / \mathrm{ml}$ increase of vitamin $D$} \\
\hline & \multicolumn{2}{|c|}{ Model 1: Unadjusted } & \multicolumn{2}{|l|}{ Model $2^{\mathrm{a}}$} \\
\hline & $\beta(95 \% C l)$ & P-value & $\beta(95 \% C l)$ & P-value \\
\hline \multicolumn{5}{|l|}{ Mets ${ }^{\mathrm{b}}$} \\
\hline Normal & Ref & & & \\
\hline MetS & $1.09(1.03-1.15)$ & 0.01 & $0.92(0.87-0.98)$ & 0.01 \\
\hline \multicolumn{5}{|l|}{$w c^{b}$} \\
\hline Normal & Ref & & & \\
\hline High & $1.05(1.00-1.11)$ & 0.04 & $0.94(0.88-0.99)$ & 0.03 \\
\hline Per $10 \mathrm{~cm}$ increase & $1.00(0.99-1.02)$ & 0.53 & $0.96(0.94-0.98)$ & 0.001 \\
\hline \multicolumn{5}{|l|}{$T G^{\mathrm{b}}$} \\
\hline Normal & Ref & & & \\
\hline High & $0.98(0.92-1.04)$ & 0.52 & $0.90(0.84-0.95)$ & 0.001 \\
\hline Per $10 \%$ increase & $1.00(1.00-1.01)$ & 0.18 & $0.99(0.99-1.00)$ & 0.002 \\
\hline \multicolumn{5}{|l|}{$B P^{\mathrm{b}}$} \\
\hline Normal & Ref & & & \\
\hline High & $1.05(0.97-1.12)$ & 0.21 & $0.93(0.86-1.00)$ & 0.06 \\
\hline Per 10 mm Hg SBP & $1.04(1.02-1.05)$ & $<0.001$ & $0.99(0.97-1.01)$ & 0.38 \\
\hline Per $10 \mathrm{~mm} \mathrm{Hg} \mathrm{DBP}$ & $1.04(1.01-1.06)$ & 0.003 & $0.96(0.94-0.99)$ & 0.02 \\
\hline \multicolumn{5}{|l|}{$H D L^{\mathrm{b}}$} \\
\hline Normal & Ref & & & \\
\hline Low & $1.08(1.03-1.14)$ & $<0.001$ & $0.99(0.94-1.05)$ & 0.81 \\
\hline Per $\mathrm{mmol} / \mathrm{l}$ increase & $1.06(0.99-1.13)$ & 0.10 & $1.12(1.03-1.21)$ & 0.01 \\
\hline \multicolumn{5}{|l|}{ Diabetes- self reported } \\
\hline No & Ref & & & \\
\hline Yes & $1.15(1.07-1.23)$ & $<0.01$ & $1.00(0.92-1.08)$ & 0.95 \\
\hline \multicolumn{5}{|l|}{ Diabetes-measured $^{\mathrm{C}}$} \\
\hline No & Ref & & & \\
\hline Yes & $1.13(1.05-1.20)$ & $<0.01$ & $0.99(0.92-1.06)$ & 0.76 \\
\hline \multicolumn{5}{|c|}{$\begin{array}{l}\text { Abbreviations: } \mathrm{BMI} \text {, body mass index; } \mathrm{BP} \text {, blood pressure; } \mathrm{HDL} \text {, high- } \\
\text { density lipids; MetS, metabolic syndrome, according to the IDF criteria; TG, } \\
\text { triglyceride; WC, waist circumference; WHR, waist-to-hip ratio. Per } \\
1 \mathrm{ng} \mathrm{ml}^{-1} \text { increase in serum vitamin D levels. Vitamin D levels were } \\
\text { logarithmic transformed in the model and the } \beta \text { were then exponentiated } \\
\text { a Model 2: Linear regression adjusted for age, sex, ethnicity, MET score, } \\
\text { education and season of blood draw. }{ }^{b} \text { Cutoffs were defined according to } \\
\text { the International Diabetes Federation. }{ }^{c} \text { Cutoff was defined according to the } \\
\text { American diabetes association. }\end{array}$} \\
\hline
\end{tabular}

\section{CONFLICT OF INTEREST}

The authors declare no conflict of interest.

\section{ACKNOWLEDGEMENTS}

Qatar Biobank is funded by the Qatar Foundation for Education, Science and Community Development. We thank all the participants and staff of Qatar Biobank for their contributions. PE and ER are supported by the Imperial College London Healthcare NHS Trust and Imperial College Biomedical Research Centre. PE is supported by the Medical Research Council and Public Health England (MRC-PHE) Centre for Environment and Health, the National Institute for Health Research (NIHR) Health Protection Research Unit on Health Impact of Environmental Hazards and is an NIHR Senior Investigator.

\section{REFERENCES}

1 Hossein-Nezhad A, Holick MF. Vitamin D for health: a global perspective. Mayo Clin Proc 2015; 88: 720-755.

2 Theodoratou E, Tzoulaki I, Zgaga L, loannidis JPA. Vitamin D and multiple health outcomes: umbrella review of systematic reviews and meta-analyses of observational studies and randomised trials. BMJ 2014; 348: 2035.

3 Holick MF. Vitamin D deficiency. N Engl J Med 2007; 357: 266-281.

4 Lips P. Relative value of 25(OH)D and 1,25(OH)2D measurements. J Bone Miner Res 2007; 22: 1668-1671.
5 Sharifi F, Mousavinasab N, Mellati AA. Defining a cutoff point for vitamin D deficiency based on insulin resistance in children. Diabetes Metab Syndr Netherlands 2013; 7: 210-213.

6 Gorham ED, Garland CF, Garland FC, Grant WB, Mohr SB, Lipkin M et al. Optimal vitamin $D$ status for colorectal cancer prevention: a quantitative meta analysis. $A m$ J Prev Med 2007; 32: 210-216.

7 Dawson-Hughes B, Heaney RP, Holick M, Lips P, Meunier PJ, Vieth R. Vitamin D round table. In: Burckhardt P, Dawson-Hughes B, Heaney R (eds). Nutritional Aspects of Osteoporosis, 2nd edn. Elsiever, Inc.: San Diego, CA, USA, 2004, pp 263-270.

8 Anderson JL, May HT, Horne BD, Bair TL, Hall NL, Carlquist JF et al. Relation of vitamin $\mathrm{D}$ deficiency to cardiovascular risk factors, disease status, and incident events in a general healthcare population. Am J Cardiol 2010; 106: 963-968.

9 Forouhi NG, Ye Z, Rickard AP, Khaw KT, Luben R, Langenberg C et al. Circulating 25-hydroxyvitamin $D$ concentration and the risk of type 2 diabetes: results from the European Prospective Investigation into Cancer (EPIC)-Norfolk cohort and updated meta-analysis of prospective studies. Diabetologia 2012; 55: 2173-2182.

10 Eliassen AH, Spiegelman D, Hollis BW, Horst RL, Willett WC, Hankinson SE. Plasma 25-hydroxyvitamin D and risk of breast cancer in the Nurses' Health Study II. Breast Cancer Res 2011; 13: R50.

11 Gandini S, Boniol M, Haukka J, Byrnes G, Cox B, Sneyd MJ et al. Meta-analysis of observational studies of serum 25-hydroxyvitamin D levels and colorectal, breast and prostate cancer and colorectal adenoma. Int J Cancer 2011; 128: 1414-1424.

12 Kayaniyil S, Harris SB, Retnakaran R, Vieth R, Knight JA, Gerstein HC et al. Prospective association of 25(OH)D with metabolic syndrome. Clin Endocrinol 2014; 80: 502-507.

13 Lu Y, Liu M, Pei Y, Li J, Tian H, Cheng X et al. Low levels of serum 25hydroxyvitamin D and risk of metabolic syndrome in China. Int J Clin Exp Med 2015; 8: 13790-13796.

14 Khan $\mathrm{H}$, Kunutsor S, Franco $\mathrm{OH}$, Chowdhury R. Vitamin D, type 2 diabetes and other metabolic outcomes: a systematic review and meta-analysis of prospective studies. Proc Nutr Soc 2013; 72: 89-97.

15 Fung GJ, Steffen LM, Zhou X, Harnack L, Tang W, Lutsey PL et al. Vitamin D intake is inversely related to risk of developing metabolic syndrome in African American and white men and women over $20 \mathrm{y}$ : the coronary artery risk development in young adults study. Am J Clin Nutr 2012; 96: 24-29.

16 Vitezova A, Zillikens MC, van Herpt TTW, Sijbrands EJG, Hofman A, Uitterlinden AG et al. Vitamin $D$ status and metabolic syndrome in the elderly: the Rotterdam Study. Eur J Endocrinol 2015; 172: 327-335.

17 Amirbaigloo A, Hosseinpanah F, Sarvghadi F, Tohidi M, Eskandary PS, Azizi F. Absence of association between vitamin D deficiency and incident metabolic syndrome: Tehran Lipid and Glucose Study. Metab Syndr Relat Disord 2013; 11: 236-242.

18 Chon SJ, Yun BH, Jung YS, Cho SH, Choi YS, Kim SY et al. Association between vitamin $\mathrm{D}$ status and risk of metabolic syndrome among Korean postmenopausal women. PLoS One 2014; 9: e89721.

19 Pekkanen MP, Ukkola O, Hedberg P, Piira OP, Lepojärvi S, Lumme J et al. Serum 25-hydroxyvitamin $D$ is associated with major cardiovascular risk factors and cardiac structure and function in patients with coronary artery disease. Nutr Metab Cardiovasc Dis 2015; 25; 471-478.

20 Park HY, Lim Y-H, Kim JH, Bae S, Oh S-Y, Hong Y-C. Association of serum 25-hydroxyvitamin $D$ levels with markers for metabolic syndrome in the elderly: a repeated measure analysis. J Korean Med Sci 2012; 27: 653-660.

21 Golbahar J, Al-Saffar N, Altayab Diab D, Al-Othman S, Darwish A, Al-Kafaji G. Predictors of vitamin $D$ deficiency and insufficiency in adult Bahrainis: a crosssectional study. Public Health Nutr 2014; 17: 732-738.

22 Alhamad HK, Nadukkandiyil N, El-Menyar A, Abdel Wahab L, Sankaranarayanan A, Al Sulaiti EM. Vitamin D deficiency among the elderly: insights from Qatar. Curr Med Res Opin 2014; 30: 1189-1196.

23 Hussain A, Alkhenizan A, El Shaker M, Raef H, Gabr A. Increasing trends and significance of hypovitaminosis D: a population-based study in the Kingdom of Saudi Arabia. Arch Osteoporos 2014; 9: 1-5.

24 Alyahya K, Lee WTK, Al-Mazidi Z, Morgan J, Lanham-New S. Risk factors of low vitamin D status in adolescent females in Kuwait: implications for high peak bone mass attainment. Arch Osteoporos 2014; 9: 178.

25 Sadiya A, Ahmed SM, Skaria S, Abusnana S. Vitamin D status and its relationship with metabolic markers in persons with obesity and type 2 diabetes in the UAE: a cross-sectional study. J Diabetes Res 2014; 2014: 869307.

26 Mahdy S, Al-Emadi SA, Khanjar IA, Hammoudeh MM, Sarakbi HA, Siam AM et al. Vitamin D status in health care professionals in Qatar. Saudi Med J 2010; 31: 74-77.

27 Bener A, Zirie M, Musallam M, Khader YS, Al-Hamaq AOAA. Prevalence of metabolic syndrome according to adult treatment panel iii and international diabetes federation criteria: a population-based study. Metab Syndr Relat Disord 2009; 7: 221-230.

28 Al Zenki S, Al Omirah H, Al Hooti S, Al Hamad N, Jackson RT, Rao A et al. High prevalence of metabolic syndrome among Kuwaiti adults--a wake-up call for public health intervention. Int J Environ Res Public Health 2012; 9: 1984-1996. 
29 Al-Lawati JA, Jousilahti P. Prevalence of metabolic syndrome in Oman using the International Diabetes Federation's Criteria. Saudi Med J 2006; 27: 1925-1926.

30 Hajat C, Shather Z. Prevalence of metabolic syndrome and prediction of diabetes using IDF versus ATPIII criteria in a Middle East population. Diabetes Res Clin Pract 2012; 98: 481-486.

31 Al-Daghri NM, Al-Attas OS, Alokail MS, Alkharfy KM, Sabico SLB, Chrousos GP. Decreasing prevalence of the full metabolic syndrome but a persistently high prevalence of dyslipidemia among adult Arabs. PLOS ONE 2010; 5: e12159.

32 Al Kuwari H, Al Thani A, Al Marri A, Al Kaabi A, Abderrahim H, Afifi $\mathrm{N}$ et al. The Qatar Biobank: background and methods. BMC Public Health 2015; 15: 1-9.

33 Holick MF, Bischoff-Ferrari H, Gordon C, Hanley D. Guidelines evaluation, treatment, and prevention of Vitamin D deficiency. J Clin Endocrinol Metab 2011; 96: 1911-1930.

34 International Diabetes Federation. The IDF consensus worldwide definition of the metabolic syndrome [Internet]. The IDF consensus worldwide definition of the metabolic syndrome. 2006; pp 1-7. Available at: http://www.idf.org/webdata/ docs/MetS_def_update2006.pdf.

35 American Diabetes Association. 2. Classification and diagnosis of diabetes. Diabetes Care; 38(Suppl 1): S8-16. Available at: http://care.diabetesjournals.org/ content/38/Supplement_1/S8.short.

36 Wang TJ, Pencina MJ, Booth SL, Jacques PF, Ingelsson E, Lanier K et al. Vitamin D deficiency and risk of cardiovascular disease. Circulation 2008; 117: 503-511.

37 Pittas AG, Dawson-Hughes B, Li T, Van Dam RM, Willett WC, Manson JE et al. Vitamin $D$ and calcium intake in relation to type 2 diabetes in women. Diabetes Care 2006; 29: 650-666.

38 McKibben RA, Zhao D, Lutsey PL, Schneider ALC, Guallar E, Mosley TH et al. Factors associated with change in 25-hydroxyvitamin D Levels Over longitudinal follow-up in the ARIC study. J Clin Endocrinol Metab 2015; 101: 33-43.

39 Hoteit M, Al-Shaar L, Yazbeck C, Bou Sleiman M, Ghalayini T, Fuleihan GE-H. Hypovitaminosis $D$ in a sunny country: time trends, predictors, and implications for practice guidelines. Metabolism 2014; 63: 968-978.

40 Gagnon C, Lu ZX, Magliano DJ, Dunstan DW, Shaw JE, Zimmet PZ et al. Low serum 25-hydroxyvitamin $D$ is associated with increased risk of the development of the metabolic syndrome at five years: results from a national, population-based prospective study (The Australian Diabetes, Obesity and Lifestyle Study: AusDiab). J Clin Endocrinol Metab 2012; 97: 1953-1961.

41 Reis JP, von Mühlen D, Miller ER. Relation of 25-hydroxyvitamin D and parathyroid hormone levels with metabolic syndrome among US adults. Eur J Endocrinol 2008; 159: 41-48.

42 Maki KC, Fulgoni VL, Keast DR, Rains TM, Park KM, Rubin MR. Vitamin D intake and status are associated with lower prevalence of metabolic syndrome in U.S. Adults: national health and nutrition examination surveys 2003-2006. Metab Syndr Relat Disord 2012; 10: 363-372.

43 Vitezova A, Voortman T, Zillikens MC, Jansen PW, Hofman A, Uitterlinden AG et al. Bidirectional associations between circulating Vitamin $\mathrm{D}$ and cholesterol levels: The Rotterdam Study. Maturitas 2015; 82: 411-417.
44 Vimaleswaran KS, Berry DJ, Lu C, Tikkanen E, Pilz S, Hiraki LT et al. Causal relationship between obesity and Vitamin $\mathrm{D}$ status: bi-directional Mendelian randomization analysis of multiple cohorts. PLoS Med 2013; 10: e1001383.

45 Majumdar V, Nagaraja D, Christopher R. Vitamin D status and metabolic syndrome in Asian Indians. Int J Obes 2011; 35: 1131-1134.

46 Reis JP, von Mühlen D, Kritz-Silverstein D, Wingard DL, Barrett-Connor E. Vitamin $D$, parathyroid hormone levels, and the prevalence of metabolic syndrome in community-dwelling older adults. Diabetes Care 2007; 30: 1549-1555.

47 Hyppönen E, Boucher BJ, Berry DJ, Power C. 25-hydroxyvitamin D, IGF-1, and metabolic syndrome at 45 years of age A cross-sectional study in the 1958 british birth cohort. Diabetes 2008; 57: 298-305.

48 Zhang M, Li P, Zhu Y, Chang H, Wang X, Liu W et al. Higher visceral fat area increases the risk of vitamin $\mathrm{D}$ insufficiency and deficiency in Chinese adults. Nutr Metab 2015; 12: 50.

49 Wortsman J, Matsuoka LY, Chen TC, Lu Z, Holick MF. Decreased bioavailability of vitamin D in obesity. Am J Clin Nutr 2000; 72: 690-693.

50 Awad AB, Alappat L, Valerio M. Vitamin D and Metabolic syndrome risk factors: evidence and mechanisms. Crit Rev Food Sci Nutr 2012; 52: 103-112.

51 Ardawi M-SM, Sibiany AM, Bakhsh TM, Qari MH, Maimani AA. High prevalence of vitamin $D$ deficiency among healthy Saudi Arabian men: relationship to bone mineral density, parathyroid hormone, bone turnover markers, and lifestyle factors. Osteoporos Int 2011; 23: 675-686.

52 Lu L, Yu Z, Pan A, Hu FB, Franco OH, Li H et al. Plasma 25-hydroxyvitamin D concentration and metabolic syndrome among middle-aged and elderly Chinese individuals. Diabetes Care 2009; 32: 1278-1283.

53 Moy F-M, Bulgiba A. High prevalence of vitamin D insufficiency and its association with obesity and metabolic syndrome among Malay adults in Kuala Lumpur, Malaysia. BMC Public Health 2011; 11: 1-7.

54 Oosterwerff MM, Eekhoff EMW, Heymans MW, Lips P, van Schoor NM. Serum 25-hydroxyvitamin $D$ levels and the metabolic syndrome in older persons: a population-based study. Clin Endocrinol 2011; 75: 608-613.

55 Ford ES, Ajani UA, McGuire LC, Liu S. Concentrations of serum Vitamin D and the metabolic syndrome among U.S. adults. Diabetes Care 2005; 28: 1228-1230.

56 World Health Organization. Qatar Stepwise Report. 2012. Available at: http://www. who.int/chp/steps/Qatar_2012_STEPwise_Report.pdf?ua $=1$.

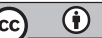

This work is licensed under a Creative Commons Attribution 4.0 International License. The images or other third party material in this article are included in the article's Creative Commons license, unless indicated otherwise in the credit line; if the material is not included under the Creative Commons license, users will need to obtain permission from the license holder to reproduce the material. To view a copy of this license, visit http://creativecommons.org/licenses/ by/4.0/

(c) The Author(s) 2017

Supplementary Information accompanies this paper on the Nutrition and Diabetes website (http://www.nature.com/nutd) 